\title{
Polyaniline-based electrospun polycaprolactone nanofibers: preparation and characterization
}

\author{
Juliana Donato de Almeida Cantalice ${ }^{1}$, Edu Grieco Mazzini Júnior¹, Johnnatan Duarte de Freitas², \\ Rosanny Christinny da Silva ${ }^{3}$, Roselena Faez ${ }^{4}$, Ligia Maria Manzine Costa ${ }^{1}$ and Adriana Santos Ribeiro ${ }^{1 *}$ (D) \\ ${ }^{1}$ Laboratório de Polímeros Condutores Eletrocrômicos e Fluorescentes, Centro de Tecnologia (Materiais), \\ Universidade Federal de Alagoas - UFAL, Maceió, AL, Brasil \\ ${ }^{2}$ Instituto Federal de Alagoas - IFAL, Campus Maceió, Maceió, AL, Brasil \\ ${ }^{3}$ Instituto Federal de Alagoas - IFAL, Campus Penedo, Penedo, AL, Brasil \\ ${ }^{4}$ Laboratório de Materiais Poliméricos e Biossorventes, Universidade Federal de São Carlos - UFSCar, \\ Campus Araras, Araras, SP, Brasil \\ *aribeiro@qui.ufal.br
}

\begin{abstract}
This work provides a convenient strategy for preparation of conducting polycaprolactone (PCL)/polyaniline (PAni) nanofibers, useful for development of optoelectronic sensors and devices. PCL/PAni nanofibers were obtained by electrospinning technique and characterized by SEM, FTIR, thermal analysis, and DC electrical conductivity. The influence of the experimental conditions in the electrospinning process, such as the applied voltage, on the nanofiber morphology was discussed in detail. Incorporation of PAni into PCL nanofibers significantly increased the electrical conductivity from a non-detectable level for the neat PCL to $0.032 \pm 0.022 \mathrm{~S} / \mathrm{cm}$ for the nanofibers containing $7.5 \mathrm{wt} . \%$ PAni. Therefore, electrospun PCL/PAni nanofiber mats presented optical and electrical properties, that awaken the possibility of applications for these materials as acid-base sensors and electrochromic devices.
\end{abstract}

Keywords: electrospinning, nanofibers, polyaniline, polycaprolactone.

How to cite: Cantalice, J. D. A., Mazzini Júnior, E. G., Freitas, J. D., Silva, R. C., Faez, R., Costa, L. M. M., \& Ribeiro, A. S. (2021). Polyaniline-based electrospun polycaprolactone nanofibers: preparation and characterization. Polímeros: Ciência e Tecnologia, 31(1), e2021002. https://doi.org/10.1590/0104-1428.09320

\section{Introduction}

Conjugated polymers which can be synthesized into one dimensional nanostructures, such as nanotubes, nanowires and nanofibers, have recently attracted attention in the areas of nanoscience and nanotechnology, due to their processability, chemical and electrochemical properties ${ }^{[1]}$. Among the various classes of conjugated polymers, polyaniline (PAni) is considered one of the most technologically promising material, owing to its high stability, easy of synthesis, excellent optical and magnetic properties, feasibility of electrical conductivity control by changing either the protonation state or the oxidation state, and the low cost of the aniline monomer ${ }^{[1-3]}$.

PAni is typically synthesized by the oxidation of aniline with ammonium peroxydisulfate in an acidic aqueous medium $^{[4]}$, and its morphology and mechanical/electrical properties are strongly affected by different experimental parameters, such as type of dopant used, $\mathrm{pH}$, temperature, and reaction time ${ }^{[5,6]}$. However, the processability of PAni to produce films or fibers is rather difficult because it is infusible and insoluble in common solvents, and thus, its practical use is limited. Significant efforts have been made in order to overcome such drawbacks and to improve the solubility, processability and mechanical properties of
PAni by changing the dopant agent ${ }^{[7]}$, blending it with other polymers ${ }^{[8]}$ or preparing hybrid organic/inorganic composites $^{[8-10]}$.

Recently, the electrospinning process has emerged as an efficient and promising technique for the preparation of polymer nanofibers with controlled diameters on the order of tens of nanometers to micrometers. It requires a simple and inexpensive setup, which can be further developed to scale up into a continuous production of nanofibers from various polymers ${ }^{[2,6,11]}$. Due to their large surface area, PAni nanofibers show enhanced water processability, improved acid-base sensitivity and response time when they are exposed to chemical vapors. Therefore, these nanofibers provide a wealth of possibilities to obtain materials with new features, including high specific surface areas, and improved properties when compared to bulk materials ${ }^{[12]}$. The high electrical conductivity of PAni associated with the high surface area and very high porosity of mats, make these materials potentially interesting for a variety of applications, for example, as multifunctional textiles, sensors, electronic devices, scaffolds for tissue engineering, and substrates for surface functionalization and modification ${ }^{[11,12]}$. 
However, the preparation of PAni nanofibers by electrospinning technique is still a great challenge due to its low solubility in common solvents, low molecular weight and rigid backbone structure ${ }^{[12,13]}$. To circumvent this problem, one of the main strategies includes blending PAni with high molecular weight polymers that serve as processing aids, such as poly(ethylene oxide) $(\mathrm{PEO})^{[14,15]}$, poly(styrene $)^{[16]}$, poly(methyl metacrylate) (PMMA) ${ }^{[11,17]}$, poly(acrylonitrile) ${ }^{[18]}$, poly(vinyl alcohol) (PVA) $)^{[19]}$, poly(lactic acid) $(\mathrm{PLA})^{[2,6]}$ and poly(caprolactone) (PCL) ${ }^{[20-22]}$.

Among polymer matrices, PCL has stimulated extensive research due to its good solubility in common solvents, low degradation rate, with non-toxic products of degradation, low melting point, superior mechanical properties, exceptional ability to form blends with various polymers in a wide range of compositions, and superior rheological and viscoelastic properties over many of its aliphatic polyester counterparts, coupled with relatively inexpensive production routes ${ }^{[20,23-26]}$.

Preparation of PCL/PAni blends aimed at applications in the biological field has been reported in the literature. Chen et al. ${ }^{[21]}$ studied the incorporation of PAni nanoparticles into PCL and gelatin blends for thermal ablation of tumor cells in vivo, Chen et al..$^{[22]}$ and $\mathrm{Ku}$ et al. ${ }^{\left[{ }^{[2]}\right.}$ used electrospun PCL/PAni nanofiber scaffolds as materials for skeletal muscle regeneration in tissue engineering. Recently, Garrudo et al. ${ }^{[28]}$ prepared PCL/PAni scaffolds for cultivation of neural stem cells. They showed that the nanofiber mats were biocompatible, which make this material an ideal candidate for in vitro neural differentiation studies under electrical stimulation.

Although most of the works described in the literature are towards the application of PCL/PAni blends in tissue engineering, the possibilities of their use are widespread, because there is a synergy between the biodegradable characteristics of PCL and the inherent conductivity of PAni. For example, such features may be useful for application in optical devices and sensors. In recent years, the research field of green electronics with focus in the development of biodegradable substrates and electrodes has demonstrating important results, since these biodegradable devices may enable the use of electronic products that can decompose after their useful lifetime ${ }^{[29]}$. Thus, PCL is a good choice regarding the fabrication of such electronic devices, as reported by Jürgensen et al. ${ }^{[29]}$ who showed that PCL reduces film roughness, provides a broad electrochemical stability window and reduction of operating voltages, and by Dierckx et al. ${ }^{[30]}$ who applied PCL/poly(3-alkylthiophene) nanofibers for optoelectronic devices.

Our research group has synthesized and characterized a series of PAni-based hybrid materials for application as electrochromic materials and optical sensors, and found interesting results, such as enhanced electrochromic properties with an intense color variation from yellow to green and blue in function of the applied potential, from blending PAni with chitosan with the incorporation of nanoclay fillers ${ }^{[9,10]}$. Therefore, the use of biopolymers along with PAni aroused considerable interest in the preparation of electrospun nanofibers for several applications in addition to the biological ones. Herein, electrospun PCL nanofibers based on PAni were prepared and characterized by structural (FTIR), morphological (SEM) and thermal analysis (TGA and DSC), aiming at applications in acid-base optoelctronic sensors.

\section{Materials and Methods}

\subsection{Materials}

Polycaprolactone (PCL, Mw 70000-90000 $\mathrm{g} \mathrm{mol}^{-1}$ ), ammonium persulfate $\left(\left(\mathrm{NH}_{4}\right)_{2} \mathrm{~S}_{2} \mathrm{O}_{8}\right)$, hydrochloric acid $(\mathrm{HCl})$, sodium hydroxide $(\mathrm{NaOH})$, dimethylsulfoxide (DMSO), chloroform $\left(\mathrm{CHCl}_{3}\right)$ and methanol $\left(\mathrm{CH}_{3} \mathrm{OH}\right)$ were purchased from Sigma-Aldrich and used as received without further purification. Aniline (Synth) was destilled before use.

\subsection{PAni synthesis}

PAni was synthesized according to the method described by Silva et al. ${ }^{[10]}$, in which $1.0 \mathrm{~mL}$ of freshly distilled aniline was dissolved in $10.0 \mathrm{~mL}$ of $1.0 \mathrm{~mol} \mathrm{~L}^{-1} \mathrm{HCl}$ and the solution was cooled to $-10^{\circ} \mathrm{C}$ in an ice, $\mathrm{NaCl}$ and ethanol bath. Then, a solution containing $3.0 \mathrm{~g}$ of $\left(\mathrm{NH}_{4}\right)_{2} \mathrm{~S}_{2} \mathrm{O}_{8}$ dissolved in 40 $\mathrm{mL}$ of $1.0 \mathrm{~mol} \mathrm{~L}^{-1} \mathrm{HCl}$ was slowly poured into the monomer solution, under vigorous stirring. The reaction temperature was maintained at $\mathrm{ca} .-10^{\circ} \mathrm{C}$ for $2 \mathrm{~h}$. After this time, a dark green precipitate was recovered from the reaction mixture by filtration under reduced pressure, washed thoroughly with $50 \mathrm{~mL}$ of $1.0 \mathrm{~mol} \mathrm{~L}^{-1} \mathrm{HCl}$, deprotonataded and dried under vacuum.

\subsection{Preparation of electrospun nanofibers}

PCL solution was prepared by dissolving $1.25 \mathrm{~g}(12.5 \mathrm{wt} \%)$ $\mathrm{PCL}$ in $5.0 \mathrm{~mL} \mathrm{CHCl}_{3}$ and then stirring for $20 \mathrm{~min}$ at $60{ }^{\circ} \mathrm{C}$. Meanwhile, $0.09 \mathrm{~g}(7.5 \mathrm{wt} \%$ with respect to the PCL $)$ of PAni previously sifted in a 60 mesh sieve was slowly dissolved in $5.0 \mathrm{~mL}$ DMSO, filtered, and then the suspension was stirred for $10 \mathrm{~min}$ at $60^{\circ} \mathrm{C}$. The PCL and PAni solutions were mixed together under stirring and sonicated for $10 \mathrm{~min}$ at $60{ }^{\circ} \mathrm{C}$ in order to ensure their homogeneity.

The electrospinning apparatus was set up inside a fume hood. It consisted of a support for a glass syringe and a static collector, wherein the polymer solution flowed through the syringe by gravity at a constant flow rate of $0.08 \mathrm{~mL} \mathrm{~min}^{-1}$. Both the syringe and needle were heated to $\mathrm{ca} .80^{\circ} \mathrm{C}$ before use. A high-voltage power supply was used to generate DC voltage up to $30 \mathrm{kV}$. The working distance between the syringe tip and collector was $12 \mathrm{~cm}$ and nanofibers were collected on aluminum foil with a collection time of 10-15 s. All samples were prepared using a needle diameter of $1.2 \mathrm{~mm}$, at temperature $25-29^{\circ} \mathrm{C}$ and relative humidity of $62-69 \%$. The optimization of the electrospinning parameters was performed according to the applied voltages $(15,17,18$ and $20 \mathrm{kV})$.

\subsection{Characterization}

The CIE (Commission Internationale de l'Eclairage) $1931 x y$ color coordinates and chromaticity diagram of the PCL/PAni mats were obtained by colorimeter app (version 3.7.7, developed by Loomatix Team, Israel) installed on an android smartphone. The measurements were based on CIE standard illuminant D65 ans standard observer $\left(2^{\circ}\right)$. The track of the CIE $1931 x y$ chromaticity coordinates in the CIE chromaticity diagram was obtained using a Spectra Lux Software v.2.0 Beta ${ }^{[31]}$.

The morphology of the samples was analyzed by Scanning Electron Microscopy (SEM) using a Vega LM TESCAN Orsay Holdin microscope, in which the samples were sputtered with gold before the analysis by a Sputter Coater (Q150T, Quorum Technologies, Darmstadt, Germany). Fiber average diameters were calculated using Image $(\mathrm{NIH}$, 
a)

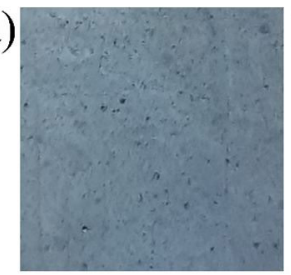

e)

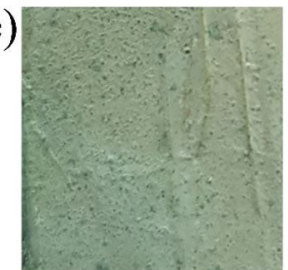

b)

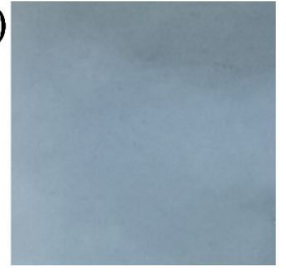

f)

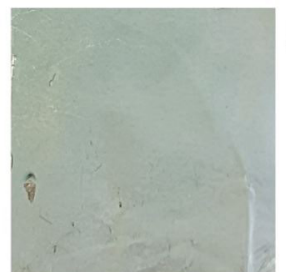

c)

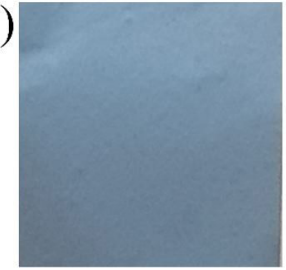

g)

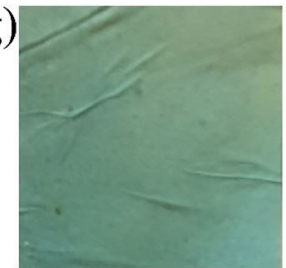

d)

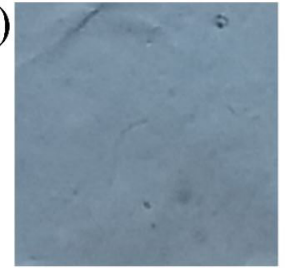

h)

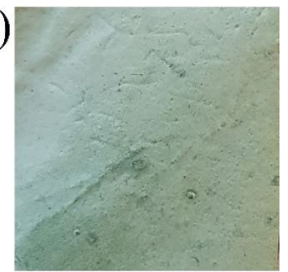

Figure 1. Images of electrospun PCL/PAni mats according to the doping state (EB or ES) and applied voltage: (a-d) EB 15, 17, 18 and $20 \mathrm{kV}$; and (e-h) ES 15,17, 18 and 20kV, respectively.

Bethesda, MD, USA), after the measurement of at least 100 fibers from each sample. FTIR spectra of the samples were obtained using an FTIR spectrometer (Nicolet 6700, Thermo Scientific). Thermogravimetric analyses (TGA) were performed on a Shimadzu thermoanalyzer TA-50, under nitrogen atmosphere with a flow of $50 \mathrm{~mL} \mathrm{~min}^{-1}$ and

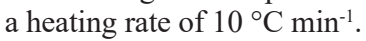

The electrical conductivity was measured by a fourpoint method using a Jandel Multi Height Probe with Jandel cylindrical probe head (25.4 $\mathrm{nm}$ diameter $\times 48.5 \mathrm{~nm}$ high), tip spacing of $1.591 \mathrm{~nm}$ controlled by the RM3-AR Test Unit. The mats $(0.05 \mathrm{~mm}$ thickness $)$ used in this measurement were prepared by applying $18 \mathrm{kV}$. Electrical conductivity of the doped and undoped mats was an average of six values of each case, measured from two sides and in different places.

\section{Results and Discussions}

The experimental conditions for electrospinning affect the morphology and the properties of the polymer nanofibers. Therefore, the results will be discussed taking into account the optimization of the electrospinning parameters and the characterization of the samples obtained in the optimized conditions.

\subsection{Morphological analysis}

The PCL/PAni nanofiber mats formed very flexible (Figure S1, Supplementary material) and stable macroscopic structures. Figure 1 shows the photographic images of undoped (emeraldine base, EB) and doped (emeraldine salt, ES) PAni based PCL mats, which displayed characteristic blue and green color, respectively. When the electrospun PCL/PAni (EB) mats were treated with $1.0 \mathrm{~mol} \mathrm{~L}^{-1} \mathrm{HCl}$ solution, their color changed from blue to green. In a similar way, when the mats were treated with $1.0 \mathrm{~mol} \mathrm{~L}^{-1} \mathrm{NH}_{4} \mathrm{OH}$ solution, their color changed from green to blue, indicating that a reversible acid-base transition occurred.

Furthermore, with the increase of the applied voltage during the electrospinning process, the color of the mats became more pronounced, except for PCL/PAni mats obtained at $15 \mathrm{kV}$, since they were macroscopically heterogeneous, presenting droplets and fibers. In this case, due to the presence of droplets in the

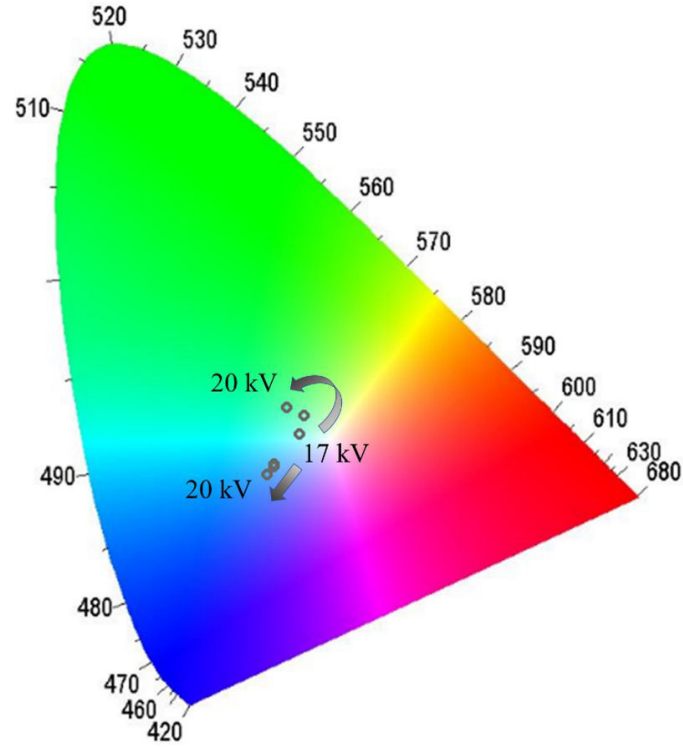

Figure 2. CIE 1931 chromaticity diagram showing the colors of PCL/PAni mats according to their oxidation (undoped/doped, blue/ green) state and the electrospinning applied potential (17,18 and $20 \mathrm{kV}$ ). The color of mats prepared at $15 \mathrm{kV}$ were not measured because they presented darker and lighter regions due to the presence of droplets on the surface.

mats surface, it was observed darker and lighter regions in the mats, and the color seen could not be accurately interpreted.

Considering the application of electrospun PCL/PAni mats as an optical $\mathrm{pH}$ sensor device, in-situ colorimetry measurements of the samples prepared at different applied potentials were performed in order to show quantitative results in terms of the color of the mats, giving a numerical description of the color stimulus, and thus providing a more precise way to define color ${ }^{[32]}$. CIE $1931(x, y)$ chromaticity coordinates changes as a function of the oxidation (undoped/ doped) state and the electrospinning applied potential are shown in Figure 2 (and Table S1, Supplementary material). 
For all samples the color reversibly changes from blue (undoped) to green (doped) in presence of $\mathrm{HCl}$, wherein this change was more significant for the PCL/PAni mat prepared at $20 \mathrm{kV}$. The results obtained for these mats show the importance of a suitable choice of the applied potential for electrospinning and further arouses the possibility of application of the material in an optical device for acidbase sensor.
The influence of the applied voltage on the formation of PCL/PAni nanofibers was assessed from the SEM images, along with their diameter distribution, as shown in Figure 3 and Table 1. It was possible to notice that defectsand beads-free electrospun fiber mats with uniform fiber diameter distributions were obtained at $18 \mathrm{kV}$. For the lowest values of the applied voltage, the fiber diameter was less homogeneous and presented some defects. For mats a)

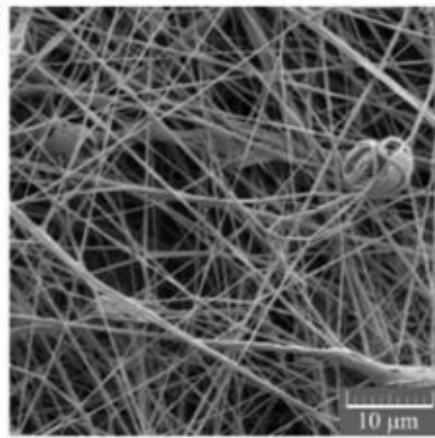

b)

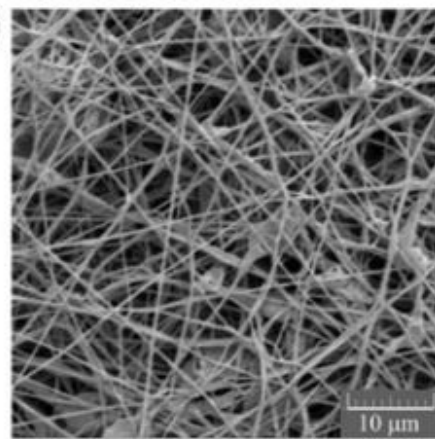

c)

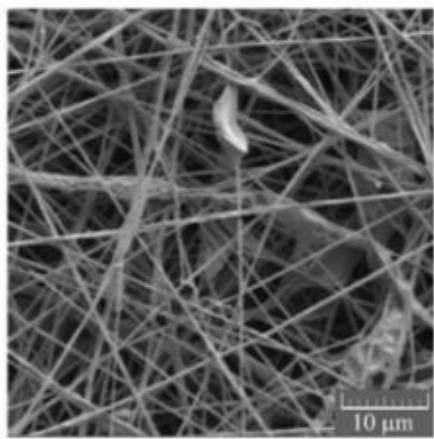

d)

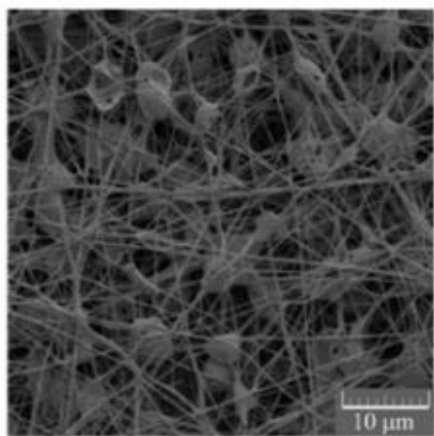

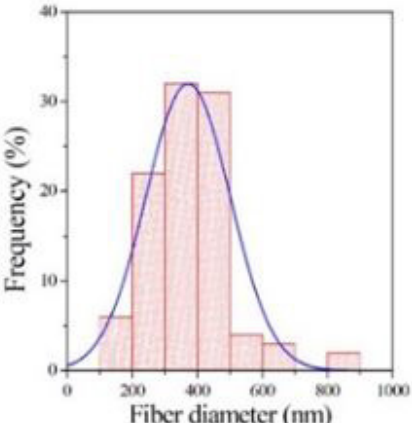
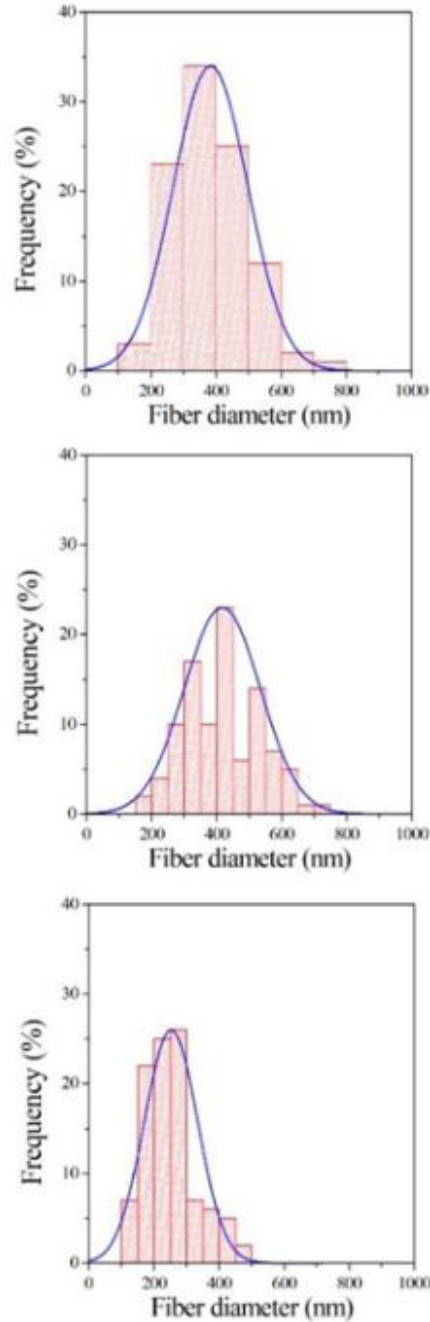

Figure 3. SEM micrographs of electrospun PCL/PAni nanofibers according to the applied voltage: (a) $15 \mathrm{kV}$; (b) $17 \mathrm{kV}$; (c) $18 \mathrm{kV}$; and (d) $20 \mathrm{kV}$. 
produced at $20 \mathrm{kV}$, it was possible to observe the formation of beads in the nanofiber morphological structure. This behavior can be explained by taking into account that at relatively low voltages, a drop is typically suspended at the needle tip, and a jet will originate from the Taylor cone producing bead-free spinning (assuming that the force of the electric field is sufficient to overcome the surface tension). As the voltage increases, the volume of the drop at the tip decreases, causing the Taylor cone to recede. The jet originates from the liquid surface within the tip, and more beading is $\operatorname{seen}^{[33]}$. Upon further increasing the voltage, the jet eventually moves around the edge of the tip, with no visible Taylor cone; at these conditions, the presence of many beads can be observed ${ }^{[20]}$.

Indeed, the SEM image of the electrospun PCL/PAni nanofibers prepared at $20 \mathrm{kV}$ exhibits a web of nanofibers with many sub-micrometer-sized spheres over the whole substrate (Figure 3d). This indicates that there are many 'nanoknots' in the hierarchical structure that link the nanofibers together, as well as many beads. A similar behavior was reported by Zhu et al. ${ }^{[16]}$ for electrospun PAni doped with azobenzene sulfonic acid/polystyrene (3.72 wt.\%) films prepared by using DMF as solvent. Thus, the best experimental conditions for smooth, homogeneous and bead-free fiber formation were found by applying $18 \mathrm{kV}$.

\subsection{Structural characterization}

The FTIR spectra of neat Pani, electrospun PCL, and PCL/PAni mats are presented in Figure 4. The PAni FTIR spectrum shows the characteristic bands at $1584 \mathrm{~cm}^{-1}$ and $1488 \mathrm{~cm}^{-1}$, which are assigned to the stretching vibration of quinoid rings and the stretching mode of benzonoid rings ${ }^{[9,10,34]}$, respectively. The bands at $1321 \mathrm{~cm}^{-1}$ refer to $\mathrm{C}-\mathrm{N}$ stretching bonds of secondary amine group ${ }^{[35]}$, whilst the bands at 1158 and $829 \mathrm{~cm}^{-1}$ are attributed to the in-plane $\mathrm{C}-\mathrm{H}$ bending of quinoid structure and the out-of-plane bending of $\mathrm{C}-\mathrm{H}$ bonds in the aromatic ring. For the electrospun PCL mats, the FTIR spectrum displays bands at $2942 \mathrm{~cm}^{-1}$ and $2864 \mathrm{~cm}^{-1}$, assigned to asymmetric and symmetric $\mathrm{C}-\mathrm{H}$ stretching, respectively. The bands at $1721 \mathrm{~cm}^{-1}, 1293 \mathrm{~cm}^{-1}, 1240 \mathrm{~cm}^{-1}$ and $1186 \mathrm{~cm}^{-1}$ are due to $\mathrm{C}=\mathrm{O}, \mathrm{C}-\mathrm{O}$ and $\mathrm{C}-\mathrm{C}$ stretching ${ }^{[36,37]}$. The FTIR spectrum

Table 1. Average fiber diameter of PCL/PAni nanofibers prepared with different applied voltage.

\begin{tabular}{cc}
\hline Applied voltage (kV) & Average fiber diameter (nm) \\
\hline 15 & $371 \pm 130$ \\
17 & $383 \pm 115$ \\
18 & $417 \pm 118$ \\
20 & $252 \pm 82$ \\
\hline
\end{tabular}

of the electrospun PCL/PAni mat presents characteristic peaks of PCL. However, due to the prevalence of PCL with respect to the amount of the PAni present in the blend, the bands related to the PAni are not clear. Magnification of the PCL/PAni FTIR spectrum (Figure 4 inset) shows the absorption peaks corresponding to the stretching modes of quinoid and benzonoid rings of the PAni. However, when compared with neat PAni, these peaks shifted to higher wavenumbers $\left(1594\right.$ and $\left.1506 \mathrm{~cm}^{-1}\right)$. This may be attributed to the interaction between PAni and PCL ${ }^{[17,38]}$.

\subsection{Thermal analysis}

Thermal analysis of the neat PAni, electrospun PCL and PCL/PAni mats by TG/DTG is discussed on basis of the results shown in Figure 5. TG analysis of the doped PAni exhibits two decomposition steps besides the water loss at temperatures lower than $100{ }^{\circ} \mathrm{C}$, which are related to the release of dopant anion $\left(\sim 300^{\circ} \mathrm{C}\right)$ and to its decomposition $\left(280-630^{\circ} \mathrm{C}\right)^{[9,39]}$. PCL nanofibers were found to be stable up to $380^{\circ} \mathrm{C}$, whereas complete degradation took place at about $460{ }^{\circ} \mathrm{C}$, with a single step trend ${ }^{[23,36]}$. Comparing the thermal behavior of the PCL/PAni with that of neat PCL, the onset of polymer decomposition occurs at a lower temperature for the hybrid material, presenting a shift of the endothermic peak from 438 to $398^{\circ} \mathrm{C}$, due to the presence of PAni. This may be related to the infuence of the volatiles from PAni ${ }^{[40]}$, which accelerate the degradation process of the mixture in a non-synergistic manner.

\subsection{Electrical conductivity}

Room temperature DC electrical conductivity values of PCL/PAni mats were measured in doped and undoped states were measured. According to Silva et al. ${ }^{[10]}$, the conductivity of PAni doped with $\mathrm{HCl}$ (pressed pellets) was $(0.70 \pm 0.20) \mathrm{S} / \mathrm{cm}$. Neat PCL nanofibers did not show detectable conductivity $\left(\sim 1.1 \times 10^{-11} \mathrm{~S} / \mathrm{cm}\right)$, as reported by Wu et al. ${ }^{[41]}$ The electrical conductivity of the PCL/PAni (EB) nanofibers was $\left(9.09 \pm 0.22 \times 10^{-6}\right) \mathrm{S} / \mathrm{cm}$, while after doping with $\mathrm{HCl}$, and the occurrence of the base-acid transition, the conductivity significantly increased to $(0.032 \pm 0.022) \mathrm{S} / \mathrm{cm}$. These results indicate homogeneous incorporation of PAni into the PCL nanofibers and they are in agreement with the conductivity values found in the literature for electrospun polymer/PAni blends, Table 2. Concerning $\mathrm{HCl}$ doped PAni blends, the electrical conductivity values found for the as prepared PCL/Pani mats in this work was higher than the reported by Wu et al. ${ }^{[41]}$ Such behavior may be attributed to the experimental conditions used for preparation of the PCL/PAni nanofibers, since these authors have electrospun a dispersion of PAni into PCL matrix without melt them.

Table 2. Electrical conductivities of PCL/PAni nanofibers.

\begin{tabular}{ccccc}
\hline Blend & PAni (\%) & Dopant & Conductivity (S/cm) & Reference \\
\hline PCL/PAni & $1.0-3.0$ & CSA & $(0.016 \pm 0.001)-(0.064 \pm 0.006)$ & 22 \\
PCL/PAni & $5-12$ & CSA & $0.042-0.077$ & 28 \\
PCL/PAni & $1.0-20$ & $\mathrm{HCl}$ & $2.8 \times 10^{-9}-2.0 \times 10^{-7}$ & 39 \\
PCL/PAni & 7.5 & $\mathrm{HCl}$ & $(0.032 \pm 0.022)$ & This work \\
\hline
\end{tabular}

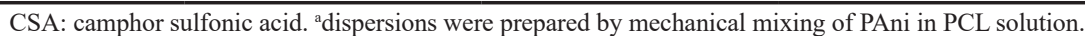




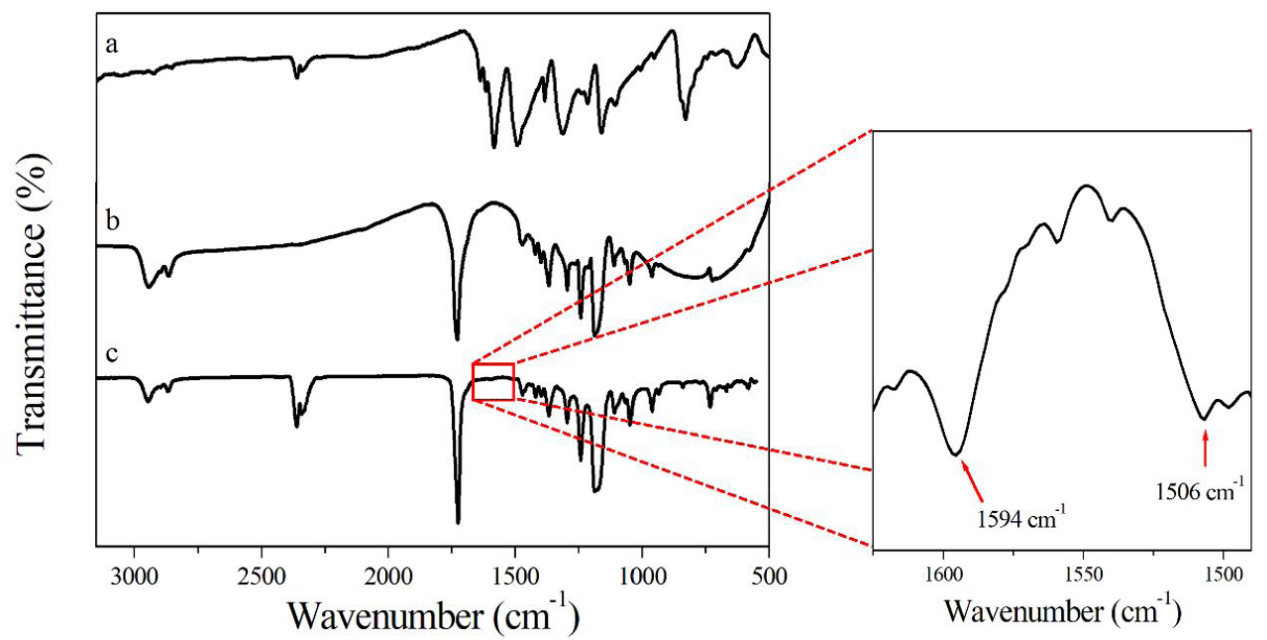

Figure 4. (a) PAni; (b) electrospun PCL mat; (c) electrospun PCL/PAni mat.
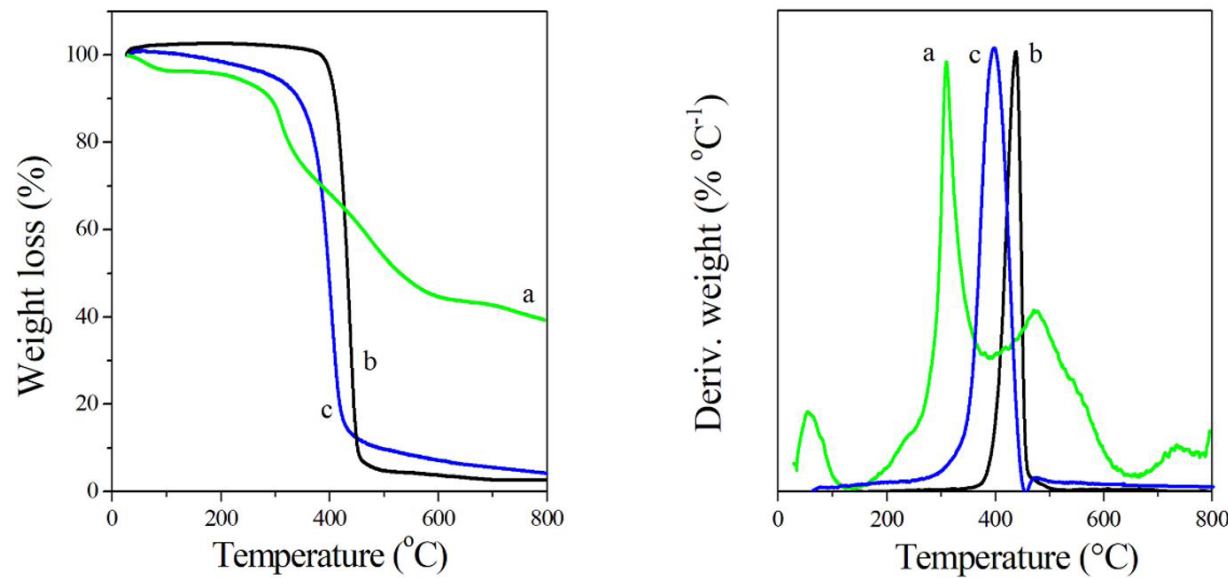

Figure 5. TG and DTG curves for (a) Pani; (b) PCL mat; and (c) PCL/PAni mat.

The changes in the electrical conductivities for the doped/dedoped PCL/PAni mats may be explained on the basis of the acid-base transition of the material. Upon exposure to $\mathrm{NH}_{4} \mathrm{OH}$, the diffusion of such molecules into the PCL/PAni mats destroys the conduction paths by swelling the polymer matrix and deprotonating PAni. The transferred electrons recombines with holes as a majority of carriers are reduced in number, thus decreasing the conductivity of PAni ${ }^{[15]}$. When an acid is employed as dopant, it may turn an insulating PAni (EB) into a conducting PAni salt as a result of the addition of a proton $\left(\mathrm{H}^{+}\right)$and a counterion for nitrogen atoms on the imine. Therefore, such PCL/PAni mats are effective materials for applying in optical and electrical acid-base sensors.

\section{Conclusions}

PCL/PAni nanofibers were successfully prepared by using a simple and versatile electrospinning technique, and they were characterized by morphological, structural, thermal, and DC conductivity analysis. The best experimental conditions for smooth, homogeneous, and bead-free fiber formation were found with 7.5 wt.\% PAni, a working distance of $12 \mathrm{~cm}$ between the syringe tip and collector, and by applying $18 \mathrm{kV}$, which resulted in a nanofiber diameter of $417 \pm 118 \mathrm{~nm}$. The electrospun mats from PCL solution containing PAni (EB) displayed blue color, whilst after doping with $\mathrm{HCl}$ it became green, which is typical of PAni (ES). The PCL/PAni (EB) mats presented a low value of electrical conductivity $\left(\left(9.09 \pm 0.22 \times 10^{-6}\right) \mathrm{S} / \mathrm{cm}\right)$, behaving as an insulating material. After doping with $\mathrm{HCl}$, and the occurrence of the base-acid transition, the conductivity significantly increased to $(0.032 \pm 0.022) \mathrm{S} / \mathrm{cm}$. This combination of a conducting PAni and electrospinnable PCL enabled the production of nanofibers that may be applied to develop new smart materials for a variety of applications that exploit optical and electrical stimulation, such as sensors and optoelectronic devices, owing to the changes in the chromaticity diagram and electrical conductivity in function of the PAni oxidation states.

\section{Acknowledgements}

The authors wish to thank the research funding agencies Conselho Nacional de Desenvolvimento Científico e Tecnológico (CNPq), Coordenação de Aperfeiçoamento de 
Pessoal de Nível Superior (CAPES) and Fundação de Amparo à Pesquisa de Alagoas (FAPEAL) for financial support.

\section{References}

1. Razak, S. I. A., Wahab, I. F., Fadil, F., Dahli, F. N., Khudzari, A. Z. M., \& Adeli, H. (2005). A review of electrospun conductive polyaniline based nanofiber composites and blends: processing, features, applications, and future directions. Advances in Materials Science and Engineering, 2005, 356286. http:// dx.doi.org/10.1155/2015/356286.

2. Picciani, P. H. S., Medeiros, E. S., Pan, Z., Orts, W. J., Mattoso, L. H. C., \& Soares, B. G. (2009). Development of conducting polyaniline/poly(lactic acid) nanofibers by electrospinning. Journal of Applied Polymer Science, 112(2), 744-753. http:// dx.doi.org/10.1002/app.29447.

3. Erden, F., Lai, S. C., Chi, H., Wang, F. K., \& He, C. (2017). Tailoring the diameters of polyaniline nanofibers for sensor application. ACS Omega, 2(10), 6506-6513. http://dx.doi. org/10.1021/acsomega.7b00544. PMid:31457252.

4. Trchová, M., Jasenská, D., Bláha, M., Prokeš, J., \& Stejskal, J. (2020). Conducting polyaniline prepared in the solutions of formic acid: does finctionalization with carboxyl groups occur? Spectrochimica Acta. Part A: Molecular and Biomolecular Spectroscopy, 235, 118300. http://dx.doi.org/10.1016/j. saa.2020.118300. PMid:32278150.

5. Gonçalves, R. V., Zanini, M. L., Malmonge, J. A., Bonnaud, L., \& Basso, N. R. S. (2018). Cashew nut shell liquid, a valuable raw material for generating semiconductive polyaniline nanofibers. Polímeros Ciência e Tecnologia, 28(1), 61-68. http://dx.doi.org/10.1590/0104-1428.01417.

6. Ashraf, S. S., Frounchi, M., \& Dadbin, S. (2020). Gamma irradiated electro-conductive polylactic acid / polyaniline nanofibers. Synthetic Metals, 259, 116204. http://dx.doi. org/10.1016/j.synthmet.2019.116204.

7. Xia, Y., Wiesinger, J. M., MacDiarmid, A. G., \& Epstein, A. J. (1995). Camphorsulfonic acid fully doped polyaniline emeraldine salt conformations in different solvents studied by an ultraviolet/visible/near-infrared spectroscopic method. Chemistry of Materials, 7(3), 443-445. http://dx.doi.org/10.1021/ cm00051a002.

8. Bhadra, J., Alkareem, A., \& Al-Thani, N. (2020). A review of advances in the preparation and application of polyaniline based thermoset blends and composites. Journal of Polymer Research, 27(5), 122. http://dx.doi.org/10.1007/s10965-02002052-1.

9. Silva, R. C., Sarmento, M. V., Nogueira, F. A. R., Tonholo, J., Mortimer, R. J., Faez, R., \& Ribeiro, A. S. (2014). Enhancing the electrochromic response of polyaniline films by the preparation of hybrid materials based on polyaniline, chitosan and organically modified clay. RSC Advances, 4(29), 1494814955. http://dx.doi.org/10.1039/C3RA47474G.

10. Silva, R. C., Sarmento, M. V., Faez, R., Mortimer, R. J., \& Ribeiro, A. S. (2016). Electrochromic properties of polyanilinebased hybrid organic/inorganic materials. Journal of the Brazilian Chemical Society, 27, 1847-1857. http://dx.doi. org/10.5935/0103-5053.20160068.

11. Zhang, Y., \& Rutledge, G. C. (2012). Electrical conductive of electrospun polyaniline and polyaniline-blend fibers and mats. Macromolecules, 45(10), 4238-4246. http://dx.doi.org/10.1021/ ma3005982.

12. Merlini, C., Pegoretti, A., Araujo, T. M., Ramoa, S. D. A. S., Schreiner, W. H., \& Barra, G. M. O. (2016). Electrospinning of doped and undoped-polyaniline/poly(vinylidene fluoride) blends. Synthetic Metals, 213, 34-41. http://dx.doi.org/10.1016/j. synthmet.2015.12.024.
13. Perdigão, P., Morais Faustino, B. M., Faria, J., Canejo, J. P., Borges, J. P., Ferreira, I., \& Baptista, A. C. (2020). Conductive electrospun polyaniline/polyvinyl pyrrolidone nanofibers: electrical and morphological characterization of new yarns for electronic textiles. Fibers, 8(4), 24. http://dx.doi.org/10.3390/ fib8040024.

14. Pinto, N. J., Johnson, A. T., Jr., MacDiarmid, A. G., Mueller, C. H., Theofylaktos, N., Robinson, D. C., \& Miranda, F. A. (2003). Electrospun polyaniline/polyethylene oxide nanofiber field effect transistor. Applied Physics Letters, 83(20), 42444246. http://dx.doi.org/10.1063/1.1627484.

15. Li, C., Chartuprayoon, N., Bosze, W., Low, K., Lee, K. H., Nam, J., \& Myung, N. V. (2014). Electrospun polyaniline/ poly (ethylene oxide) composite nanofibers based gas sensor. Electroanalysis, 26(4), 711-722. http://dx.doi.org/10.1002/ elan.201300641.

16. Zhu, Y., Zhang, J., Zheng, Y., Huang, Z., Feng, L., \& Jiang, L. (2006). Stable, superhydrophobic, and conductive polyaniline/ polystyrene films for corrosive environments. Advanced Functional Materials, 16(4), 568-574. http://dx.doi.org/10.1002/ adfm.200500624.

17. Zhao, Y., Zhang, Z., Yu, L., \& Tang, Q. (2016). Electrospinning of polyaniline microfibers for anticorrosion coatings: an avenue of enhancing anticorrosion behaviors. Synthetic Metals, 212, 84-90. http://dx.doi.org/10.1016/j.synthmet.2015.12.007.

18. Matysiak, W., Tanski, T., Smok, W., Golombek, K., \& SchabBalcerzak, E. (2020). Effect of conductive polymers on the optical properties of electrospun polyacrylonitrile nanofibers filled by polypyrrole, polythiophene and polyaniline. Applied Surface Science, 509, 145068. http://dx.doi.org/10.1016/j. apsusc.2019.145068.

19. Shahi, M., Moghimi, A., Naderizadeh, B., \& Maddah, B. (2011). Electrospun PVA-PANI and PVA-PANI-AgNO composite nanofibers. Scientia Iranica C, 18(6), 1327-1331. http://dx.doi.org/10.1016/j.scient.2011.08.013.

20. Shadi, L., Karimi, M., Ramazani, S., \& Entezami, A. A. (2014). Preparation of electrospun nanofibers of star-shaped polycaprolactone and its blends with polyaniline. Journal of Materials Science, 49(14), 4844-4854. http://dx.doi.org/10.1007/ s10853-014-8185-4.

21. Chen, Y., Li, C., Hou, Z., Huang, S., Liu, B., He, F., Luo, L., \& Lin, J. (2015). Polyaniline electrospinning composite fibers for orthotopic photothermal treatment of tumors in vivo. New Journal of Chemistry, 39(6), 4987-4993. http://dx.doi. org/10.1039/C5NJ00327J.

22. Chen, M.-C., Sun, Y.-C., \& Chen, Y.-H. (2013). Electrically conductive nanofibers with highly oriented structures and their potential application in skeletal muscle tissue engineering. Acta Biomaterialia, 9(3), 5562-5572. http://dx.doi.org/10.1016/j. actbio.2012.10.024. PMid:23099301.

23. Liverani, L., \& Boccaccini, A. R. (2016). Versatile production of poly(epsilon-caprolactone) fibers by electrospinning using benign solvents. Nanomaterials, 6(4), 75. http://dx.doi. org/10.3390/nano6040075. PMid:28335202.

24. Xue, J., Wu, T., Dai, Y., \& Xia, Y. (2019). Electrospinning and electrospun nanofibers: methods, materials, and applications. Chemical Reviews, 119(8), 5298. http://dx.doi.org/10.1021/ acs.chemrev.8b00593. PMid:30916938.

25. Ninago, M. D., Ciolino, A. E., \& Villar, M. A. (2020). Improvement in poly(e-caprolactone) bio-activity. Structural characterization and in vitro assessment. International Journal of Polymeric Materials and Polymeric Biomaterials, 69(4), 201-210. http://dx.doi.org/10.1080/00914037.2018.1552864.

26. Woodruff, M. A., \& Hutmacher, D. W. (2020). The return of a forgotten polymer: polycaprolactone in the $21^{\text {st }}$ century. 
Progress in Polymer Science, 35(10), 1217-1256. http://dx.doi. org/10.1016/j.progpolymsci.2010.04.002.

27. Ku, S. H., Lee, S. H., \& Park, C. B. (2012). Synergic effects of nanofiber alignment and electroactivity on myoblast differentiation. Biomaterials, 33(26), 6098-6104. http://dx.doi. org/10.1016/j.biomaterials.2012.05.018. PMid:22681977.

28. Garrudo, F. F. F., Chapman, C. A., Hoffman, P. R., Udangawa, R. W., Silva, J. C., Mikael, P. E., Rodrigues, C. A. V., Cabral, J. M. S., Morgado, J. M. F., Ferreira, F. C., \& Linhardt, R. J. (2019). Polyaniline-polycaprolactone blended nanofibers for neural cell culture. European Polymer Journal, 117, 28-37. http://dx.doi.org/10.1016/j.eurpolymj.2019.04.048.

29. Jürgensen, N., Zimmermann, J., Morfa, A. J., \& Hernandez-Sosa, G. (2016). Biodegradable polycaprolactone as ion solvating polymer for solution-processed light-emitting electrochemical cells. Scientific Reports, 6(1), 36643. http://dx.doi.org/10.1038/ srep36643. PMid:27811991.

30. Dierckx, W., Oosterbaan, W. D., Bolsée, J.-C., Maes, W., Vanderzande, D., \& Manca, J. (2014). Poly(3-alkylthiophene) nanofibers for optoelectronic devices. Journal of Materials Chemistry. C, Materials for Optical and Electronic Devices, 2(29), 5730-5746. http://dx.doi.org/10.1039/c4tc00308j.

31. Santa-Cruz, P. A., \& Teles, F. S. (2003). Spectra Lux Software v. 2.0 Beta, Ponto Quântico Nanodispositivos/RENAMI, Brasil. Recife: UFPE.

32. Wyszecki, G., \& Stiles, W. S. (1982). Color science: concepts and methods, quantitative data and formulae (2nd ed). New York: John Wiley \& Sons.

33. Deitzel, J. M., Kleinmeyer, J., Harris, D., \& Tan, N. C. B. (2001). The effect of processing variables on the morphology of electrospun nanofibers and textiles. Polymer, 42(1), 261272. http://dx.doi.org/10.1016/S0032-3861(00)00250-0.

34. Asturias, G. E., MacDiarmid, A. G., McCall, R. P., \& Epstein, A. J. (1989). The oxidation state of "emeraldine" base. Synthetic Metals, 29(1), 157-162. http://dx.doi.org/10.1016/03796779(89)90291-9.

35. Cao, Y., Li, S., Xue, Z., \& Guo, D. (1986). Spectroscopic and electrical characterization of some aniline oligomers and polyaniline. Synthetic Metals, 16(3), 305-315. http://dx.doi. org/10.1016/0379-6779(86)90167-0.

36. Mazzini, E. G., Jr. \& Cantalice, J. D., Assis, A. M. L., Freitas, J. D., Costa, L. M. M., \& Ribeiro, A. S. (2020). Fluorescent polymer nanofibers based on polycaprolactone and dansyl derivatives for development of latent fingerprints. Journal of Applied Polymer Science, 137(46), 49804. http://dx.doi. org/10.1002/app.49804.

37. Ramírez-Cedillo, E., Ortega-Lara, W., Rocha-Pizaña, M. R., Gutierrez-Uribe, J. A., Elías-Zúñiga, A., \& Rodríguez, G. A. (2019). Electrospun polycaprolactone fibrous membranes containing $\mathrm{Ag}, \mathrm{TiO}_{2}$ and $\mathrm{Na}_{2} \mathrm{Ti}_{6} \mathrm{O}_{13}$ particles for potential use in bone regeneration. Membranes, $9(1), 12$. http://dx.doi. org/10.3390/membranes9010012. PMid:30634630.

38. Gu, B. K., Kim, M. S., Kang, C. M., Kim, J.-I., Park, S. J., \& Kim, C.-H. (2014). Fabrication of conductive-polymer-based nanofiber scaffolds for tissue engineering applications. Journal of Nanoscience and Nanotechnology, 14(10), 7621-7626. http:// dx.doi.org/10.1166/jnn.2014.9575. PMid:25942837.

39. Kulkarni, M. V., \& Viswanath, A. K. (2004). Scanning electron microscopy, spectroscopy, and thermal studies of polyaniline doped with various sulfonic acids. Journal of Macromolecular Science, Part A: Pure and Applied Chemistry, 41(10), 11731186. http://dx.doi.org/10.1081/MA-200026566.

40. Traore, M. K., Stevenson, W. T. K., McCormick, B. J., Dorey, R. C., Wen, S., \& Meyers, D. (1991). Thermal analysis of polyaniline Part I. Thermal degradation of HCl-doped emeraldine base. Synthetic Metals, 40(2), 137-153. http:// dx.doi.org/10.1016/0379-6779(91)91770-B.

41. Wu, J. C.-C., Ray, S., Gizdavic-Nikolaidis, M., Uy, B., Swift, S., Jin, J., \& Cooney, R. P. (2014). Nanostructured bioactive material based on polycaprolactone and polyaniline fiber-scaffolds. Synthetic Metals, 198, 41-50. http://dx.doi. org/10.1016/j.synthmet.2014.09.017.

Received: Oct. 19, 2020

Revised: Jan. 14, 2021

Accepted: Feb. 12, 2021 


\section{Supplementary Material}

Supplementary material accompanies this paper.

Figure S1. Image of electrospun PCL/PAni flexible mat.

Table S1. Colorimetry data (CIE 1931 xy color coordinates) of PCL/PAni mats prepared at different applied potential and in their undoped and doped states.

This material is available as part of the online article from http://www.scielo.br/polimeros 